\title{
Eficácia do S-metolachlor associado à ametrina e hexazinona+diuron no controle pré e pós-emergente de plantas daninhas em cana-de-açúcar ${ }^{1}$
}

Efficacy of s-metolachlor associated to ametryn and hexazinone+diuron in controlling pre and

post-emergent of weeds in sugar cane

Eigon Costa dos Santos $^{2}$, Priscila Alves de Souza ${ }^{2}$, Fernando Tadeu de Carvalho ${ }^{3}$

Resumo - O trabalho teve como objetivo avaliar em cana-de-açúcar a seletividade e a eficácia do herbicida S-metolachlor associado à ametrina e [hexazinona+diuron], aplicados via terrestre e via aérea, no controle pré e pós-emergente de plantas daninhas. O delineamento utilizado no experimento 1 (aplicação terrestre) foi o de blocos ao acaso com 16 tratamentos e quatro repetições, aplicados em pré e pós-emergência com: S-metolachlor + ametrina $(1920+1500$; $2400+1500$ e $2880+1500$ g i.a. ha $\left.{ }^{-1}\right) ;$ S-metolachlor + [hexazinona+diuron] $(1440+[702+198]$ e $1920+[702+198]$ g i.a. ha $\left.{ }^{-1}\right) ;\left[\right.$ hexazinona+diuron] + ametrina $\left([936+264]+1500\right.$ g i.a. ha $\left.{ }^{-1}\right)$; tebuthiuron + ametrina $\left(1000+1500 \mathrm{~g}\right.$ i.a. $\left.\mathrm{ha}^{-1}\right)$ e as testemunhas capinada e sem capina. No experimento 2 (aplicação aérea), os tratamentos foram: S-metolachlor $\left(2880 \mathrm{~g}\right.$ i.a. ha $\left.{ }^{-1}\right), \mathrm{S}$ metolachlor + ametrina $\left(2400+1500 \mathrm{~g}\right.$ i.a. ha $\left.^{-1}\right)$ e testemunha sem aplicação, sendo os herbicidas aplicados em duas faixas de um hectare para cada tratamento. Todos os tratamentos herbicidas provocaram fitotoxicidade inicial à cana-de-açúcar (RB 835486), com recuperação total aos 45 DAA (dias após aplicação). A aplicação terrestre em pré-emergência de S-metolachlor + ametrina, S-metolachlor + [hexazinona+diuron], [hexazinona+diuron] + ametrina e tebuthiuron + ametrina foi eficiente no controle de Digitaria horizontalis, Ipomoea nil e Amaranthus deflexus. Em pós-emergência, os tratamentos foram menos eficientes no controle de $D$. horizontalis; mais eficientes no controle de $I$. nil e equivalentes no controle de A. deflexus. A aplicação área de Smetolachlor e S-metolachlor + ametrina foi eficiente no controle de $D$. horizontalis e $B$. plantaginea, proporcionando produtividade da cana-de-açúcar superior a testemunha sem herbicidas.

Palavras-chave: Aplicação terrestre; aplicação aérea; mistura em tanque; Saccharum spp.

\begin{abstract}
The work aimed to evaluate, in sugar cane crop, the selectivity and effectiveness of S-metolachlor herbicide associated to ametryn and [hexazinone+diuron], applied terrestrial and aerial forms, in pre and post emergent weeds control. The experimental design used in experiment 1 (terrestrial application) was randomized complete blocks with 16 treatments and four repetitions, applied in pre and post emergence: S-metolachlor + ametryn $(1920+1500$; $2400+1500$ and $2880+1500 \mathrm{~g}$ a.i. ha $^{-1} ;$ S-metolachlor + [ hexazinone+diuron ] $(1440+[$

\footnotetext{
${ }^{1}$ Recebido para a publicação em 15/03/2011 e na forma revisada em 18/08/2011.

${ }^{2}$ Pós-graduandos de Agronomia, FEIS-UNESP, Ilha Solteira/SP. E-mail: eigon1@ @otmail.com; pri_souza19@hotmail.com

${ }^{3}$ Professor Dr., DBZ-FEIS-UNESP, Ilha Solteira/SP, Brasil. E-mail: ftadeu@ bio.feis.unesp.br
}

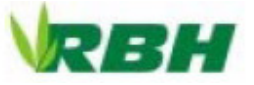


$702+198]$ and $1920+\left[702+198\right.$ ] g a.i. ha $^{-1} ;$ [ hexazinone+diuron ] + ametryn $([$ 936+264 ] + $1500 \mathrm{~g}$ a.i. $\mathrm{ha}^{-1}$; tebuthiuron + ametryn $\left(1000+1500 \mathrm{~g}\right.$ a.i. $\mathrm{ha}^{-1}$ and checks with and without weeding. In experiment 2 (aerial application), the treatments were constituted by S-metolachlor $\left(2880 \mathrm{~g}\right.$ a.i. $\left.\mathrm{ha}^{-1}\right)$, S-metolachlor + ametryn $\left(2400+1500 \mathrm{~g}\right.$ a.i. ha $\left.{ }^{-1}\right)$ and checks without application, being herbicides applied in two bands of one hectare for each treatment. All herbicides treatments caused initial phytotoxicity to sugar cane crop (RB 835486), with total recovery at 45 DAA (days after application). Terrestrial application in S-metolachlor + ametryn, S-metolachlor + [hexazinone+diuron], [hexazinone+diuron] + ametryn and tebuthiuron + ametryn pre-emergence was efficient in controlling Digitaria horizontalis, Ipomoea nil and Amaranthus deflexus. In post emergency, treatments were less efficient in controlling $D$. horizontalis; more efficient in controlling I. nil and equivalents in A. deflexus control. Aerial application of S-metolachlor and S-metolachlor + ametryn was efficient in D. horizontalis e $B$. plantaginea control, providing higher sugar cane yield than the check without herbicides application.

Keywords: Terrestrial application; aerial application; tank mixture; Saccharum spp.

\section{Introdução}

O Brasil é o maior produtor de cana-deaçúcar do mundo. Segundo dados do IBGE (2011) a área de cultivo de cana-de-açúcar do Brasil na safra 2010/11 foi de 9 milhões de hectares sendo a maior concentração no Estado de São Paulo com 5 milhões de hectares.

O grande potencial edafoclimático do Brasil é uma das condições favoráveis à produção agrícola e em especial à cana-deaçúcar. Entretanto, existe uma série de fatores que podem prejudicar a sua produção. Um dos pontos críticos no processo produtivo da cultura é a interferência imposta pelas plantas daninhas ao competirem com a cultura por nutrientes, água e luz, dificultar o corte e a colheita, diminuindo a qualidade do produto colhido e reduzindo a longevidade do canavial (Kuva et al., 2003).

As plantas daninhas destacam-se pelos efeitos negativos causados na produtividade, devido à concorrência por fatores essenciais como água e nutrientes e os efeitos alelopáticos que podem prejudicar o desenvolvimento das plantas (Cruz \& Leiderman, 1978; Clement et al., 1979; Victória Filho \& Camargo, 1980; Kuva et al., 2003).
As plantas de cana-de-açúcar possuem uma particularidade que lhes permite desenvolver-se bem em diferentes situações de manejo: cana-planta; cana-soca sem palha; cana-soca com palha; cana de $3^{\circ}, 4^{\circ}$ cortes, etc. Entretanto, esta grande variação nos fatores ecológicos proporciona nichos adequados para um grande número de espécies daninhas, o que torna a cana-de-açúcar diferente da maioria das outras plantas cultivadas. Desta forma, os herbicidas precisam apresentar um amplo espectro de controle para se adequar às exigências da cultura e, neste aspecto, tornamse importantes as misturas de herbicidas que se enquadram exatamente neste contexto.

O herbicida S-metholachlor é um inibidor da divisão celular indicado para o controle pré-emergente de plantas daninhas, com ação acentuada sobre gramíneas e algumas dicotiledôneas (Rodrigues \& Almeida, 2005). A parceria de S-metholachlor com outros herbicidas residuais pode ser uma boa opção para a cultura da cana-de-açúcar tanto economicamente, como na eficácia de controle das plantas daninhas.

O objetivo do trabalho foi avaliar em cana-de-açúcar a seletividade e a eficácia do herbicida S-metolachlor associado a ametrina e hexazinona+diuron, aplicados via terrestre e via 
aérea, no controle pré e pós-emergente de plantas daninhas.

\section{Material e Métodos}

O trabalho foi desenvolvido no período de novembro/2006 a julho/2007, na área de cultivo da Usina Vale do Paraná, situada à $20^{\circ} 23^{\prime} 48^{\prime \prime}$ de latitude sul, $51^{\circ} 00^{\prime} 09^{\prime \prime}$ de longitude oeste e 395 metros de altitude, no município de Suzanápolis, na região noroeste do Estado de São Paulo. O solo da área experimental foi classificado como Latossolo Vermelho, textura média, constituído por $25 \%$ de argila, $67 \%$ de areia e $8 \%$ de silte.

Dois experimentos foram desenvolvidos em área de cana-soca ( $1^{\mathrm{o}}$ corte - variedade RB 835486) com espaçamento de $1,4 \mathrm{~m}$ entrelinhas, colhida em 15/11/2006 (15 e 30 dias antes das aplicações dos tratamentos pré e pós-emergentes). Os tratos culturais realizados na área experimental, no que diz respeito às adubações e ao controle de pragas, foram os normais exigidos pela cultura e realizados na área de cultivo.

O delineamento utilizado no experimento 1 (aplicação terrestre) foi o de blocos ao acaso com 16 tratamentos e quatro repetições, aplicados em pré e pós-emergência com: S-metolachlor + ametrina $(1920+1500$; $2400+1500$ e $2880+1500$ g i.a. ha $\left.{ }^{-1}\right)$; Smetolachlor + [hexazinona+diuron] $(1440+$ $[702+198]$ e $1920+[702+198]$ g i.a. ha $\left.{ }^{-1}\right) ;$ [hexazinona+diuron] + ametrina $([936+264]+$ 1500 g i.a. ha $\left.{ }^{-1}\right)$; tebuthiuron + ametrina $(1000$ $+1500 \mathrm{~g}$ i.a. ha ${ }^{-1}$ ) e as testemunhas capinadas ("no limpo") e sem capina ("no mato"). Cada parcela constou de quatro linhas da cultura com $5 \mathrm{~m}$ de comprimento e $5 \mathrm{~m}$ de largura, totalizando $25 \mathrm{~m}^{2}$, com $20 \mathrm{~m}^{2}$ de área aplicada.

As aplicações dos herbicidas foram realizadas com um pulverizador costal pressurizado $\left(\mathrm{CO}_{2}\right.$ a $\left.40 \mathrm{lb} / \mathrm{pol}^{2}\right)$, provido de tanque com capacidade de dois litros ("garrafas PET") e com barra equipada com quatro bicos do tipo leque Teejet $110.03 \mathrm{XR}$, espaçados de $0,5 \mathrm{~m}$, proporcionando um consumo de calda aplicado de $200 \mathrm{~L} \mathrm{ha}^{-1}$. Na aplicação em pósemergência, as plantas daninhas encontravamse em pleno vigor vegetativo, com as gramíneas na fase de primeiro perfilho e as dicotiledôneas com 2 a 3 pares de folhas. Aos 120 DAA (dias após aplicação), as espécies Digitaria horizontalis (capim-colchão) e Ipomoea nil (corda-de-viola) estavam finalizando o ciclo e o Amaranthus deflexus finalizou seu desenvolvimento aos 75 DAA, conforme demonstrado na Tabela 1.

Tabela 1. Infestação média das plantas daninhas. Suzanápolis, SP (2006/07).

\begin{tabular}{|rccccc|}
\hline \multirow{3}{*}{ Espécie daninha } & \multicolumn{5}{c|}{ \% Média de Infestação nas Testemunhas no Mato } \\
\cline { 2 - 6 } & 15 DAA pré & 30 DAA pré & 60 DAA pré & 75 DAA pré & 120 DAA pré \\
\cline { 2 - 6 } & 0 DAA pós & 15 DAA pós & 45 DAA pós & 60 DAA pós & 105 DAA pós \\
\hline Digitaria horizontalis & 15,0 & 41,3 & 50,0 & 62,5 & 60,0 \\
\hline Ipomoea nil & 10,0 & 10,0 & 10,0 & 10,0 & 12,5 \\
\hline Amaranthus deflexus & 22,5 & 27,5 & 30,0 & 25,0 & -- \\
\hline TOTAL & 47,5 & 78,8 & 90 & 72,5 & 72,5 \\
\hline
\end{tabular}

DAA = Dias Após a Aplicação.

No experimento 2 (aplicação aérea), os hectare para cada tratamento. As quatro tratamentos foram: S-metolachlor $(2880 \mathrm{~g}$ i.a. testemunhas sem herbicidas foram obtidas $\left.\mathrm{ha}^{-1}\right)$, S-metolachlor + ametrina $(2400+1500 \mathrm{~g}$ colocando-se sobre o solo lonas plástica (Figura i.a. $\left.\mathrm{ha}^{-1}\right)$ e testemunha sem aplicação, sendo os 1) com dimensões de $8 \times 10 \mathrm{~m}\left(80 \mathrm{~m}^{2}\right)$. As herbicidas aplicados em duas faixas de 1 lonas foram fixadas com quatro estacas de 
madeira, para evitar o seu deslocamento na mesmas dimensões $\left(80 \mathrm{~m}^{2}\right)$ ao lado das passagem do avião, e após as aplicações as testemunhas (Figura 2), sendo todas as parcelas lonas foram retiradas e as estacas mantidas, georeferenciadas, o que possibilitou localizá-las demarcando as parcelas. Os tratamentos com nas avaliações subsequentes.

herbicidas foram avaliados em parcelas com as
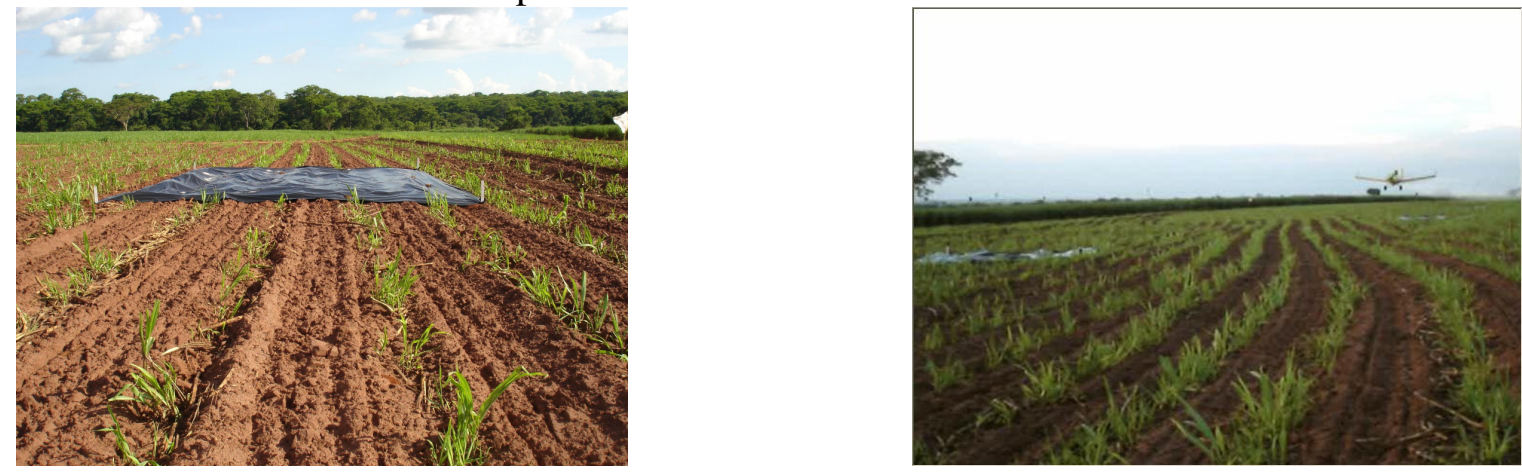

Figura 1. Lonas plásticas para obtenção da parcela testemunha sem herbicida (à esquerda) e momento da aplicação aérea (à direita). Suzanápolis, SP (2006/07).

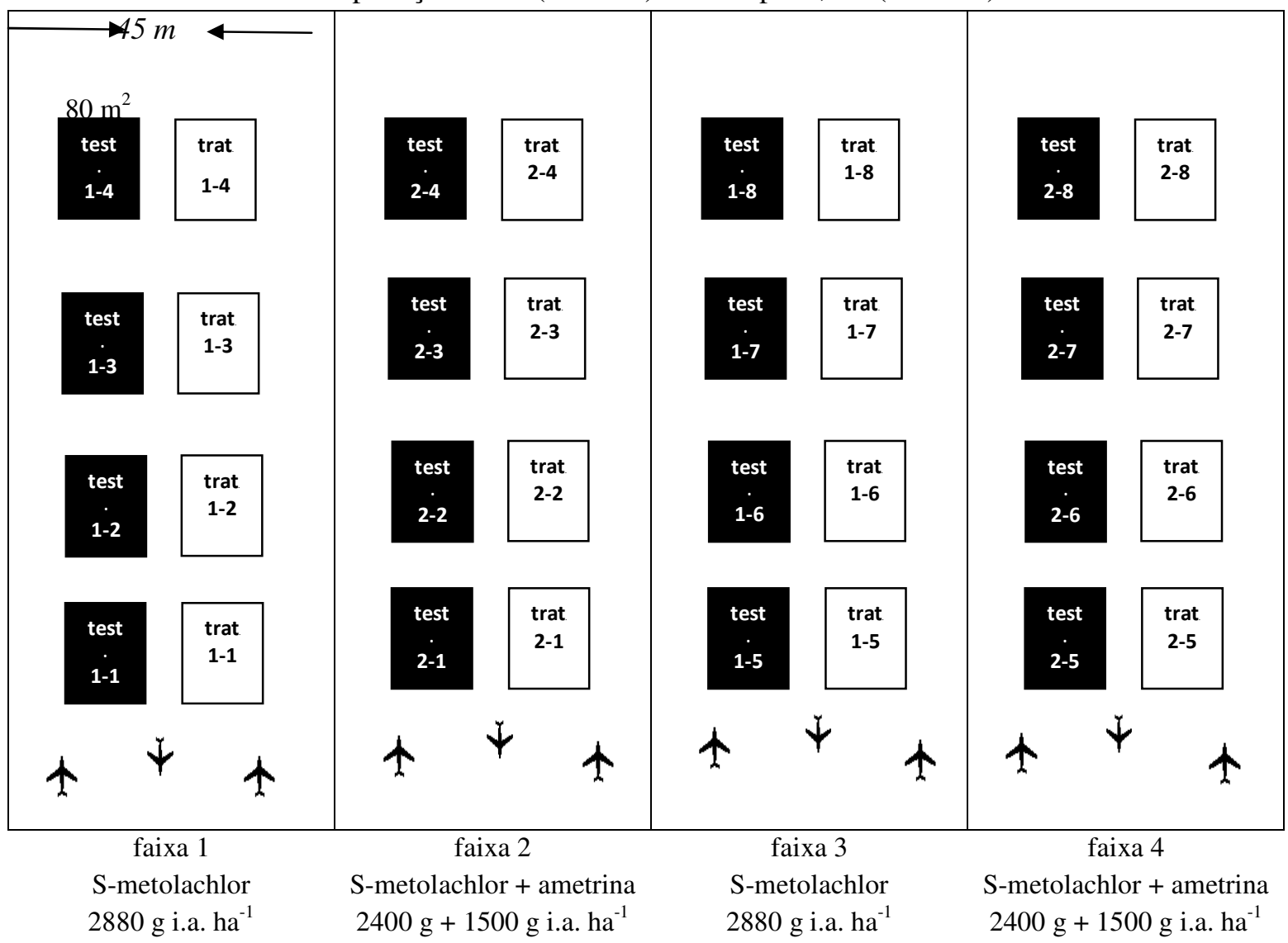

Figura 2. Croqui da área experimental. Experimento 2 (aplicação aérea). Suzanápolis, SP (2006/07). 
Considerando o tipo de aplicação (em faixas) e o delineamento utilizado na aplicação aérea, o experimento 2 foi convencionado em dois blocos, com três tratamentos e dezesseis repetições para o tratamento 1 (Testemunha sem herbicidas) e oito repetições para os tratamentos 2 (S-metolachlor: 2880 g i.a. ha ${ }^{-1}$ ) e 3 (S-metolachlor + ametrina: $2400+1500$ g i.a. $\left.\mathrm{ha}^{-1}\right)$. A análise estatística dos dados de biometria e produtividade da cultura foi realizada pelo teste de Tukey a $5 \%$, com números diferentes de repetições. $\mathrm{O}$ croqui da área experimental (experimento 2) está apresentado na Figura 2.

As aplicações foram realizadas com um avião agrícola modelo EMB-201A (Ipanema), operando à $180 \mathrm{~km} \mathrm{~h}^{-1}$, com "by-pass" regulado

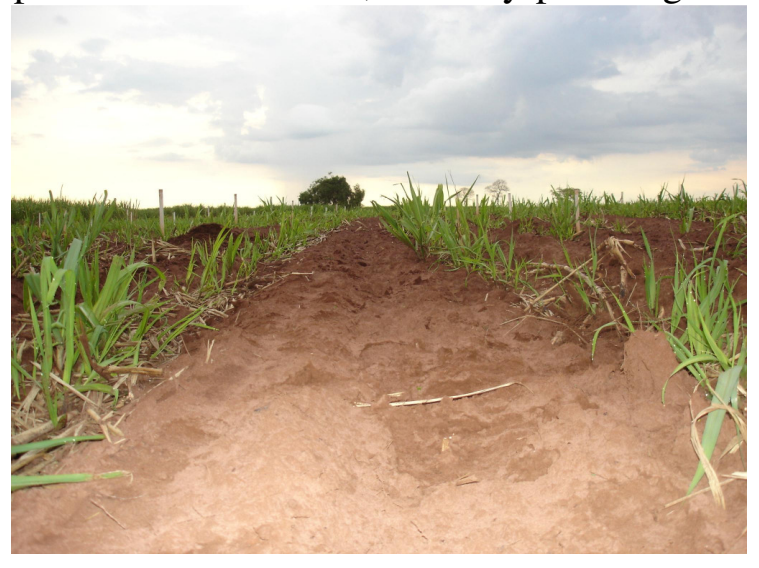

Pré-emergência para pressão na barra de $30 \mathrm{lb} / \mathrm{pol}^{2}$ e barra equipada com 38 bicos do tipo cônico, com ponta D-12 e core 45 , posicionados à $160^{\circ} \mathrm{em}$ relação ao ângulo de vôo. O volume de calda aplicado foi de 40 litros por hectare e faixa de trabalho de 15 metros, com altura de vôo de 4 metros, que proporcionou gotas de tamanho médio a grande $(400 \mu \mathrm{m})$, em densidade média de 20 gotas por $\mathrm{cm}^{2}$.

As aplicações dos herbicidas foram realizadas em pré (experimentos 1 e 2) e pós-emergência (experimento 1) das plantas daninhas (Figura 3), e as condições edafoclimáticas no momento das aplicações estão descritas na Tabela 2.

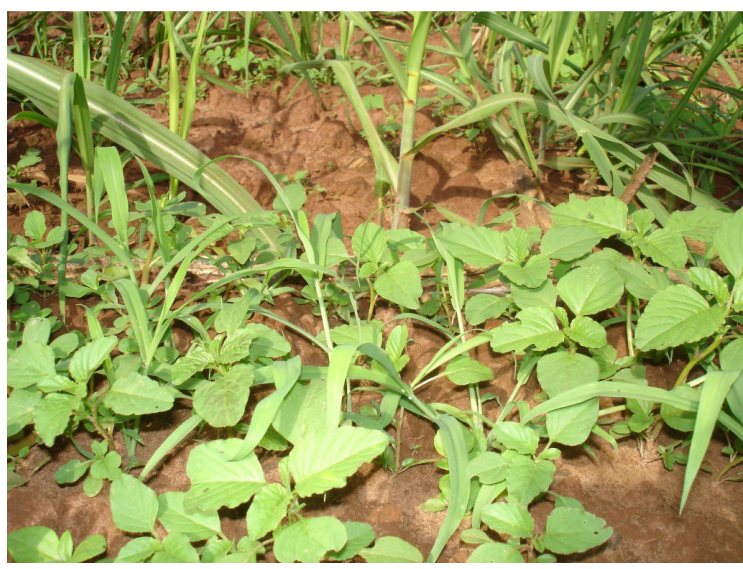

Pós-emergência

Figura 3. Condições da área experimental nas aplicações. Suzanápolis, SP (2006/07).

Tabela 2. Condições edafoclimáticas nas aplicações. Suzanápolis, SP (2006/07).

\begin{tabular}{|ccccccc|}
\hline Aplicação & Data & Horário & Solo & Temp. ar & UR ar & Vento \\
\hline pré: terrestre & $30 / 11 / 06$ & $8: 00-9: 00$ & c/ umidade & $27^{\circ} \mathrm{C}$ & $85 \%$ & $<2 \mathrm{~km} / \mathrm{h}$ \\
pré: aérea & $30 / 11 / 06$ & $18: 30-19: 30$ & c/ umidade & $29^{\circ} \mathrm{C}$ & $65 \%$ & Brisa \\
\hline pós: terrestre & $15 / 12 / 06$ & $18: 30-19: 30$ & c/ umidade & $30^{\circ} \mathrm{C}$ & $88 \%$ & $<2 \mathrm{~km} / \mathrm{h}$ \\
\hline
\end{tabular}

A pluviometria ocorrida na área experimental, 15 dias antes das aplicações em Pré e Pósemergência, encontra-se representada na Tabela 3. 
Tabela 3. Precipitações ocorridas antes das aplicações. Suzanápolis, SP (2006/07).

\begin{tabular}{|c|c|c|c|c|c|c|c|c|c|c|c|c|}
\hline \multicolumn{10}{|c|}{ Chuvas (mm) ocorridas antes das aplicações em pré e pós-emergência } \\
\hline $02 / 11$ & $03 / 11$ & $04 / 11$ & $06 / 11$ & $08 / 11$ & $09 / 11$ & $19 / 11$ & $20 / 11$ & $27 / 11$ & $28 / 11$ & $29 / 11$ & $30 / 11$ \\
\hline 31,5 & 16,8 & 11,2 & 19,6 & 0,2 & 0,3 & 0,3 & 2,0 & 1,8 & 44,7 & 24,4 & $\begin{array}{c}\text { Aplicação } \\
\text { pré }\end{array}$ \\
\hline $01 / 12$ & $03 / 12$ & $04 / 12$ & $05 / 12$ & $07 / 12$ & $08 / 12$ & $09 / 12$ & $10 / 12$ & $13 / 12$ & $14 / 12$ & $01 / 12$ & $15 / 12$ \\
\hline 11,9 & 63,0 & 38,4 & 20,3 & 15,0 & 30,5 & 7,9 & 0,3 & 2,8 & 29,5 & 11,9 & $\begin{array}{c}\text { Aplicação } \\
\text { pós }\end{array}$ \\
\hline
\end{tabular}

A eficiência dos tratamentos no controle das plantas daninhas foi avaliada aos 15, 30, 60, 75 e 120 dias após a aplicação (DAA) terrestre e aos 30, 60 e 120 DAA aérea. A avaliação foi realizada utilizando-se uma escala visual, onde $0 \%$ representa nenhum controle e $100 \%$ controle total das plantas daninhas, conforme metodologia descrita pela SBCPD (1995). Considerou-se como eficiente o controle igual ou superior a $80 \%$ aos 120 DAA, época do fechamento da cultura. A seletividade dos tratamentos às plantas da cultura foi avaliada visualmente considerando-se a biomassa e a coloração das plantas tratadas comparadas com as plantas da testemunha e atribuindo-se notas de $0 \%$ a $100 \%$, onde $0 \%$ representou nenhum sintoma de fitotoxicidade e $100 \%$ a morte total das plantas.

As análises de biometria das plantas da cultura e de produtividade foram realizadas no experimento 2 (aplicação aérea). Foram avaliadas as características do desenvolvimento da cultura, aos 8 meses após o corte, analisando-se o número de colmos em 2 metros lineares; a altura de plantas medida do colo ao último gomo e o diâmetro do segundo gomo em 10 plantas seguidas, por parcela. A avaliação de produtividade foi realizada coletando-se e pesando-se 10 colmos de cana-de-açúcar da área central de cada parcela.

\section{Resultados e discussão}

\section{Experimento 1: Aplicação terrestre}

Os dados de controle das plantas daninhas do experimento 1 encontram-se representados na Tabela 4. Observa-se que todos os tratamentos foram eficientes no controle das plantas daninhas quando aplicados em pré-emergência. Em pósemergência, os tratamentos foram menos eficientes no controle da gramínea $D$. horizontalis; foram mais eficientes no controle de I. nil e foram equivalentes no controle de $A$. deflexus, quando comparados com a aplicação em pré-emergência.

Para a espécie $D$. horizontalis os tratamentos foram altamente eficientes no controle pré-emergente proporcionando níveis médios de controle acima de $99 \%$ aos 120 DAA. Em pós-emergência os tratamentos foram menos eficientes de maneira geral e, o tratamento S-metolachlor + [hexazinona+diuron] $(1440+[702+198]$ e 1920 $\mathrm{g}+[702+198] \mathrm{g}$ i.a. $\left.\mathrm{ha}^{-1}\right)$ foi ineficiente no controle de $D$. horizontalis, proporcionando níveis médios de eficácia inferiores a $65 \%$, aos 120 DAA. Deve-se, porém, ressaltar que o Smetolachlor é recomendado exclusivamente para a aplicação em pré-emergência (Rodrigues \& Almeida, 2005) e o [hexazinona+diuron] também é mais eficiente em pré-emergência (Lorenzi et al., 2006). Para a modalidade de aplicação em pós-emergência, as misturas em tanque com ametrina foram importantes para a manutenção da eficácia de controle. Os tratamentos S-metolachlor + ametrina, [hexazinona+diuron] + ametrina e tebuthiuron + ametrina foram eficientes no controle pós- 
emergente da planta daninha proporcionando níveis médios de controle acima de $85 \%$, aos 120 DAA.

Para a espécie $I$. nil todos os tratamentos foram eficientes no controle pré e pósemergente da planta daninha. Os níveis médios de controle obtidos foram acima de $90 \%$, exceto s-metolachlor + ametrina na menor dose $\left(1920 \mathrm{~g}+1500 \mathrm{~g}\right.$ i.a. ha $\left.{ }^{-1}\right)$ que proporcionou controle de $82 \%$, aos 120 DAA. Para esta espécie ressalta-se uma pequena melhora na eficácia dos tratamentos quando aplicados em pós-emergência. Segundo Lorenzi et al. (2006),

Tabela 4. Controle das plantas daninhas no experimento. Suzanápolis, SP.

\begin{tabular}{|c|c|c|c|c|}
\hline \multirow{3}{*}{ Tratamentos } & \multirow{3}{*}{$\begin{array}{l}\text { Dosagem } \\
\left(\text { g i.a. ha }{ }^{-1}\right)\end{array}$} & \multicolumn{3}{|c|}{$\%$ CONTROLE } \\
\hline & & D. horizontalis & I. nil & A. deflexus \\
\hline & & $120 \mathrm{DAA}$ & $120 \mathrm{DAA}$ & 75 DAA \\
\hline 01- testemunha sem aplicação ("no mato") & $\overline{--}$ & $\overline{0,0} \mathrm{c}$ & $0,0 \mathrm{~d}$ & $0,0 \mathrm{c}$ \\
\hline 02- testemunha capinada ("no limpo") & -- & 100,0 a & 100,0 a & 100,0 a \\
\hline 03- S-metolachlor + ametrina (PRÉ) & $1920+1500$ & 100,0 a & $82,0 \quad \mathrm{c}$ & $99,0 \mathrm{ab}$ \\
\hline 04- S-metolachlor + ametrina (PRÉ) & $2400+1500$ & 100,0 a & $90,0 \quad b$ & $99,0 \mathrm{ab}$ \\
\hline 05- S-metolachlor + ametrina (PRÉ) & $2880+1500$ & 100,0 a & $95,0 \mathrm{ab}$ & 100,0 a \\
\hline 06- S-metolachlor + [hexazinona+diuron] (PRÉ) & $1440+[702+198]$ & 99,0 a & $97,0 \mathrm{ab}$ & $99,0 \mathrm{ab}$ \\
\hline 07- S-metolachlor + [hexazinona+diuron] (PRÉ) & $1920+[702+198]$ & 99,0 a & 96,0 ab & 100,0 a \\
\hline 08- [hexazinona+diuron] + ametrina (PRÉ) & {$[936+264]+1500$} & 100,0 a & 98,0 a & 100,0 a \\
\hline 09- tebuthiuron + ametrina (PRÉ) & $1000+1500$ & 99,0 a & $97,0 \mathrm{ab}$ & $99,0 \mathrm{ab}$ \\
\hline 10- S-metolachlor + ametrina (PÓS) & $1920+1500$ & 85,0 a & 98,0 a & 99,5 a \\
\hline 11- S-metolachlor + ametrina (PÓS) & $2400+1500$ & 86,5 a & 100,0 a & 99,5 a \\
\hline 12- S-metolachlor + ametrina (PÓS) & $2880+1500$ & 95,3 a & 100,0 a & $100,0 \mathrm{a}$ \\
\hline 13- S-metolachlor + [hexazinona+diuron] (PÓS) & $1440+[702+198]$ & $50,0 \mathrm{~b}$ & 100,0 a & 99,5 a \\
\hline 14- S-metolachlor + [hexazinona+diuron] (PÓS) & $1920+[702+198]$ & $65,0 \mathrm{~b}$ & 100,0 a & 100,0 a \\
\hline 15- [hexazinona+diuron] + ametrina (PÓS) & {$[936+264]+1500$} & 96,3 a & 99,0 a & $99,0 \mathrm{ab}$ \\
\hline 16- tebuthiuron + ametrina (PÓS) & $1000+1500$ & 95,0 a & 99,0 a & $98,0 \quad b$ \\
\hline Média Geral (4 repetições) & & $85,62 \%$ & $90,69 \%$ & $93,22 \%$ \\
\hline Teste f (tratamentos) & & $60,65 * *$ & $270,88 * *$ & $8771,45^{* *}$ \\
\hline Coeficiente de Variação & & $8,08 \%$ & $3,30 \%$ & $0,57 \%$ \\
\hline DMS (5\%) & & 17,74 & 7,67 & 1,36 \\
\hline
\end{tabular}

DAA= Dias Após a Aplicação; - Médias seguidas de mesma letra na coluna não diferem entre si pelo teste de Tukey a 5\% de probabilidade. $*=$ significativo $5 \% ; * *$ significativo $1 \%$;

Os dados médios de fitotoxicidade dos tratamentos estão apresentados na Tabela 5. Observa-se que todos os herbicidas provocaram o herbicida ametrina é mais eficaz no controle de espécies do gênero Ipomoea, quando aplicado em pós-emergência inicial. Correa et al. (2006) também observaram controle satisfatório $(>85 \%)$ de dicotiledôneas com o tratamento hexazinona+diuron aplicado em pós-emergência inicial.

Para a espécie A. deflexus, todos os tratamentos pré e pós-emergentes foram altamente eficientes, proporcionando níveis médios de controle superiores a $98 \%$, aos 75 DAA. 
não foi mais observado nenhum sintoma às plantas da cultura. $O$ maior índice de fitotoxicidade $(\%)$ foi observado para o tratamento [hexazinona+diuron] + ametrina $\left([936+264]+1500\right.$ g i.a. ha $\left.{ }^{-1}\right)$, que proporcionou $15 \%$ injúrias sobre os aspectos visuais aos 15 DAA, na aplicação em pósemergência.

Tabela 5. Fitotoxicidade dos tratamentos às plantas da cultura. Suzanápolis, SP (2006/07).

\begin{tabular}{|c|c|c|c|c|}
\hline \multirow[b]{2}{*}{ Tratamentos } & \multirow{2}{*}{$\begin{array}{l}\text { Dosagem } \\
\left.\text { (g i.a. ha }^{-1}\right)\end{array}$} & \multicolumn{3}{|c|}{ \% Fitotoxicidade } \\
\hline & & 15 DAA & 30 DAA & $45 \mathrm{DAA}$ \\
\hline 01- testemunha sem aplicação ("no mato") & -- & $0,0 \mathrm{~d}$ & $0,0 \mathrm{c}$ & $\overline{0,0}$ \\
\hline 02- testemunha capinada ("no limpo") & -- & $0,0 \mathrm{~d}$ & $0,0 \mathrm{c}$ & 0,0 \\
\hline 03- S-metolachlor + ametrina (PRÉ) & $1920+1500$ & $4,5 \mathrm{bc}$ & $0,0 \mathrm{c}$ & 0,0 \\
\hline 04- S-metolachlor + ametrina (PRÉ) & $2400+1500$ & 4,8 bc & $0,3 \mathrm{bc}$ & 0,0 \\
\hline 05- S-metolachlor + ametrina (PRÉ) & $2880+1500$ & 5,0 bc & $0,5 \mathrm{bc}$ & 0,0 \\
\hline 06- S-metolachlor + [hexazinona+diuron] (PRÉ) & $1440+[702+198]$ & 4,0 bcd & $2,3 \mathrm{bc}$ & 0,0 \\
\hline 07- S-metolachlor + [hexazinona+diuron] (PRÉ) & $1920+[702+198]$ & $4,5 \mathrm{bc}$ & $2,5 \mathrm{bc}$ & 0,0 \\
\hline 08- [hexazinona+diuron] + ametrina (PRÉ) & {$[936+264]+1500$} & $6,0 \mathrm{~b}$ & $2,5 \mathrm{bc}$ & 0,0 \\
\hline 09- tebuthiuron + ametrina (PRÉ) & $1000+1500$ & 5,0 bc & $1,3 \mathrm{bc}$ & 0,0 \\
\hline 10- S-metolachlor + ametrina (PÓS) & $1920+1500$ & $6,0 \mathrm{~b}$ & $2,5 \mathrm{bc}$ & 0,0 \\
\hline 11- S-metolachlor + ametrina (PÓS) & $2400+1500$ & $7,0 \mathrm{~b}$ & $3,0 \mathrm{~b}$ & 0,0 \\
\hline 12- S-metolachlor + ametrina (PÓS) & $2880+1500$ & $7,3 \mathrm{~b}$ & $3,0 \mathrm{~b}$ & 0,0 \\
\hline 13- S-metolachlor + [hexazinona+diuron] (PÓS) & $1440+[702+198]$ & $1,3 \mathrm{~cd}$ & 1,0 bc & 0,0 \\
\hline 14- S-metolachlor + [hexazinona+diuron] (PÓS) & $1920+[702+198]$ & $1,5 \mathrm{~cd}$ & $1,0 \mathrm{bc}$ & 0,0 \\
\hline 15- [hexazinona+diuron] + ametrina (PÓS) & {$[936+264]+1500$} & 15,0 a & 8,3 a & 0,0 \\
\hline 16- tebuthiuron + ametrina (PÓS) & $1000+1500$ & $8,0 \mathrm{~b}$ & $3,0 \mathrm{~b}$ & 0,0 \\
\hline Média Geral (4 repetições) & & $1000+1500$ & $2,94 \%$ & $\overline{--}$ \\
\hline Teste f (tratamentos) & & $19,90^{* *}$ & $12,59 * *$ & -- \\
\hline Coeficiente de Variação & & $32,67 \%$ & $59,47 \%$ & -- \\
\hline DMS (5\%) & & 4,17 & 2,95 & -- \\
\hline
\end{tabular}

DAA= Dias Após a Aplicação; - Médias seguidas de mesma letra na coluna não diferem entre si pelo teste de Tukey a 5\% de probabilidade. $*=$ significativo $5 \%$; $* *$ significativo $1 \%$;

\section{Experimento 2: Aplicação aérea}

Os dados de eficácia dos tratamentos na aplicação aérea e as porcentagens de infestações das plantas daninhas nas testemunhas estão apresentados na Tabela 6. As espécies daninhas avaliadas na área experimental foram a $D$. horizontalis (capimcolchão) e B. plantaginea (capim-marmelada).
Observa-se que o herbicida Smetolachlor $\left(2880 \mathrm{~g}\right.$ i.a. ha $\left.^{-1}\right)$ foi eficiente no controle de D. horizontalis e B. plantaginea, proporcionando níveis médios de controle de $82,5 \%$ e $85,5 \%$, aos 120 DAA. Esses resultados indicam que o S-metolachlor é uma opção eficaz para o controle de espécies gramíneas $(D$. horizontalis e $B$. plantaginea) e, neste caso, vale ressaltar que a rapidez da aplicação aérea pode viabilizar a utilização do herbicida que necessita ser aplicado em pré-emergência total 
das plantas daninhas, devido ao seu mecanismo $94,5 \%$ e 95,5\%, respectivamente, para $D$. de ação. horizontalis e $B$. plantaginea, aos 120 DAA. A O tratamento S-metolachlor + ametrina $\left(2400+1500 \mathrm{~g}\right.$ i.a. $\left.\mathrm{ha}^{-1}\right)$ foi altamente eficiente no controle das plantas daninhas, eficácia elevada do tratamento para $D$. proporcionando níveis médios de controle de horizontalis já havia sido observada no Tabela 6. Proporção da infestação das plantas daninhas e eficácia dos tratamentos herbicidas. Suzanápolis, SP (2006/07).

\begin{tabular}{|c|c|c|c|c|}
\hline \multirow{2}{*}{ TRATAMENTOS } & \multirow{2}{*}{$\begin{array}{c}\text { Dosagem } \\
\left(\text { g i.a. }^{-1}{ }^{-1}\right)\end{array}$} & \multicolumn{3}{|c|}{ Digitaria horizontalis } \\
\hline & & 30 DAA & $60 \mathrm{DAA}$ & 120 DAA \\
\hline 1- Testemunha sem herbicidas & -- & $\begin{array}{c}18,4 \% \\
\text { (infestação) }\end{array}$ & $\begin{array}{c}20,0 \% \\
\text { (infestação) }\end{array}$ & $\begin{array}{c}31,9 \% \\
\text { (infestação) }\end{array}$ \\
\hline 2- S-metolachlor & 2880 & $\begin{array}{c}85,4 \% \\
\text { (controle) }\end{array}$ & $\begin{array}{c}83,5 \% \\
\text { (controle) }\end{array}$ & $\begin{array}{c}82,5 \% \\
\text { (controle) }\end{array}$ \\
\hline 3- S-metolachlor + ametrina & $2400+1500$ & $\begin{array}{c}98,4 \% \\
\text { (controle) }\end{array}$ & $\begin{array}{c}95,8 \% \\
\text { (controle) }\end{array}$ & $\begin{array}{c}94,5 \% \\
\text { (controle) }\end{array}$ \\
\hline \multirow{2}{*}{ TRATAMENTOS } & Dosagem & \multicolumn{3}{|c|}{ Brachiaria plantaginea } \\
\hline & $\left(\right.$ g i.a. ha $\left.^{-1}\right)$ & $30 \mathrm{DAA}$ & $60 \mathrm{DAA}$ & $120 \mathrm{DAA}$ \\
\hline 1- Testemunha sem herbicidas & -- & $\begin{array}{c}14,4 \% \\
\text { (infestação) }\end{array}$ & $\begin{array}{c}16,9 \% \\
\text { (infestação) }\end{array}$ & $\begin{array}{c}29,4 \% \\
\text { (infestação) }\end{array}$ \\
\hline 2- S-metolachlor & 2880 & $\begin{array}{c}88,6 \% \\
\text { (controle) }\end{array}$ & $\begin{array}{c}86,5 \% \\
\text { (controle) }\end{array}$ & $\begin{array}{c}85,5 \% \\
\text { (controle) }\end{array}$ \\
\hline 3- S-metolachlor + ametrina & $2400+1500$ & $\begin{array}{c}98,5 \% \\
\text { (controle) }\end{array}$ & $\begin{array}{c}97,6 \% \\
\text { (controle) }\end{array}$ & $\begin{array}{c}95,5 \% \\
\text { (controle) } \\
\end{array}$ \\
\hline
\end{tabular}

DAA= Dias Após a Aplicação

Os dados médios de fitotoxicidade dos herbicidas estão apresentados na Tabela 7. Observa-se que os herbicidas provocaram sintomas muito leves de fitotoxicidade às plantas de cana-de-açúcar. Aos 30 DAA os sintomas foram quase nulos e, aos 45 DAA, não foi mais observado nenhum sintoma às plantas da cultura.

Tabela 7. Fitotoxicidade dos tratamentos para cultura da cana-de-açúcar (RB 835486). Suzanápolis, SP (2006/07).

\begin{tabular}{|lcccc|}
\hline \multirow{2}{*}{ Tratamentos } & \multirow{2}{*}{$\begin{array}{c}\text { Dosagem } \\
\left(\mathrm{g} \mathrm{i.a.} \mathrm{ha}^{-1}\right)\end{array}$} & \multicolumn{3}{c|}{ \% Fitotoxicidade } \\
\cline { 3 - 5 } & -- & 0,0 & 0,0 & 0,0 \\
\hline 1- Testemunha sem herbicidas & 2880 & 1,5 & 0,5 & 0,0 \\
\hline 2- S-metolachlor & $2400+1500$ & 3,5 & 1,0 & 0,0 \\
\hline 3- S-metolachlor + ametrina & & &
\end{tabular}

DAA= Dias Após a Aplicação

Os dados de biometria e produtividade da cultura estão apresentados na Tabela 8. Observa-se que as plantas daninhas prejudicaram o crescimento e a produtividade da cultura nos tratamentos testemunhas sem herbicidas. Os dados de biometria, referentes ao diâmetro e altura de colmos e número de perfilhos, assim como de produtividade, observados para S-metolachlor (2880 g i.a. ha $\left.{ }^{1}\right)$ e S-metolachlor + ametrina $(2400+1500 \mathrm{~g}$ i.a. $\mathrm{ha}^{-1}$ ) foram significativamente superiores aos observados nas testemunhas sem 
herbicidas. Destaca-se que o tratamento $\mathrm{S}$ metolachlor + ametrina $\left(2400+1500\right.$ g i.a. ha ${ }^{-}$ $\left.{ }^{1}\right)$ proporcionou os maiores índices de produtividade em função da maior eficácia no controle das plantas daninhas.

$$
\text { Os dados observados }
$$

comprovam os prejuízos que as plantas

Tabela 8. Biometria e estimativa de produção da cultura. Suzanápolis, SP (2006/07).

\begin{tabular}{|c|c|c|c|c|c|}
\hline \multirow[b]{2}{*}{ Tratamentos } & \multirow[b]{2}{*}{$\begin{array}{l}\text { Dosagem } \\
\left(\text { g i.a. ha }^{-1}\right)\end{array}$} & \multicolumn{4}{|c|}{8 Meses Após a Colheita } \\
\hline & & $\begin{array}{l}\text { Diâmetro } \\
(\mathrm{mm})\end{array}$ & $\begin{array}{l}\text { Altura } \\
(\mathrm{cm})\end{array}$ & $\begin{array}{c}\mathrm{N}^{\mathrm{o}} \mathrm{de} \\
\text { perfilhos /m }\end{array}$ & $\begin{array}{l}\text { Produtividade } \\
\qquad\left(\mathrm{t} \mathrm{ha}^{-1}\right)\end{array}$ \\
\hline 1- Testemunha sem herbicidas & -- & $24,6 \mathrm{~b}$ & $250,93 \mathrm{~b}$ & $12,80 \mathrm{~b}$ & $82,50 \mathrm{~b}$ \\
\hline 2- S-metolachlor & 2880 & $26,4 \mathrm{a}$ & 261,03 a & $15,44 \mathrm{a}$ & 115,09 a \\
\hline 3- S-metolachlor + ametrina & $2400+1500$ & $27,4 \mathrm{a}$ & 267,60 a & $14,75 \mathrm{a}$ & $123,64 \mathrm{a}$ \\
\hline Média Geral & & 27,75 & 257,62 & 13,94 & 100,93 \\
\hline Teste f (tratamentos) & & $28,08 * *$ & $12,43 * *$ & $10,33 * *$ & $31,30 * *$ \\
\hline Coeficiente de Variação & & $3,53 \%$ & $3,12 \%$ & $10,86 \%$ & $13,23 \%$ \\
\hline
\end{tabular}

DAA= Dias Após a Aplicação; - Médias seguidas de mesma letra na coluna não diferem entre si pelo teste de Tukey a 5\% de probabilidade. $*=$ significativo $5 \%$; $* *$ significativo $1 \%$;

\section{Conclusões}

Todos os tratamentos herbicidas provocaram sintomas de fitotoxicidade inicial à cultura da cana-de-açúcar variedade RB 835486, com recuperação total aos 45 DAA.

A aplicação terrestre em pré-emergência de S-metolachlor + ametrina, S-metolachlor + [hexazinona+diuron], [hexazinona+diuron] + ametrina e tebuthiuron + ametrina foi eficiente no controle de $D$. horizontalis, $I$. nil e $A$. deflexus. Em pós-emergência, os tratamentos foram menos eficientes no controle de $D$. horizontalis; mais eficientes no controle de $I$. nil e equivalentes no controle de A. deflexus, em relação a aplicação em pré-emergência.

A aplicação área de S-metolachlor e Smetolachlor + ametrina foi eficiente no controle de $D$. horizontalis e $B$. plantaginea, proporcionando produtividade da cana-deaçúcar superior a testemunha sem herbicidas. daninhas causam à cultura da cana-de-açúcar, já observados por diversos outros autores (Cruz \& Leiderman, 1978; Clement et al., 1979; Victória Filho \& Camargo, 1980; Fornarolli et al., 1997).

\section{Referências}

CORREA, M.R. et al. Controle de plantas daninhas pelo herbicida diuron+hexazinone em aplicações de pós-emergência em período chuvoso. In: CONGRESSO BRASILEIRO DA CIÊNCIA DAS PLANTAS DANINHAS, 25, 2006, Brasília, DF, Resumos... Brasília, DF: SBCPD, 2006. p. 349.

CLEMENT, A.A. et al. Controle de plantas daninhas em cana-de-açúcar (Saccharum officinarum) com hexazinone e suas misturas com diuron, em pré-emergência. Planta Daninha, v.2, n.2, p.89-95, 1979.

CONAB-MAPA. Acompanhamento da Safra Brasileira - Cana-de-Açúcar - Safra 2007/2008. Primeiro Levantamento, Maio/2007.

http://www.conab.gov.br/conabweb/ download/safra/1levan_cana07.pdf. Acesso em: 15/07/07.

Instituto Brasileiro de Geografia e Estatística IBGE. Levantamento Sistemático da Produção Agrícola - Cana-de-Açúcar - Safra 
2011.

http://www.ibge.gov.br/home/ estatistica/indicadores/agropecuaria. Acesso em: 15/03/2011.

CRUZ, L.S.P.; LEIDERMAN, L. Competição entre quatro herbicidas indicados para $\mathrm{O}$ controle de plantas daninhas em cana-de-açúcar (Saccharum spp.). Planta Daninha, v.1, n.2, p.43-48, 1978.

FORNAROLLI, D.A. et al. Controle do Sorghum arundinaceum em pós-emergência inicial e tardia com o uso de MSMA+diuron na cultura da cana-de-açúcar (Saccharum spp.). In: CONGRESSO BRASILERO DA CIÊNCIA DAS PLANTAS DANINHAS, 21, 1997, Caxambú - MG, Resumos... Viçosa MG: SBCPD, 1997. p. 259.

KUVA, M.A. et al. Períodos de interferência das plantas daninhas na cultura da cana-deaçúcar. III - capim-braquiária (Brachiaria decumbens) e capim-colonião (Panicum maximum). Planta Daninha, v.21, n.1, p.3744, 2003.

LORENZI, H. et al. Manual de Identificação e controle de plantas daninhas: plantio direto e convencional, $6^{\mathbf{a}}$ ed., Nova Odessa, SP: Plantarum, 2006. 339p.

RODRIGUES, B.N.; ALMEIDA, F.S. Guia de herbicidas. $5^{\text {a }}$ ed., Londrina: Edição dos Autores, 2005. 592 p.

VICTÓRIA FILHO, R., CAMARGO, P.N. Efeito de herbicidas nos teores de macronutrientes e nas características tecnológicas da cana-de-açúcar (Saccharum spp.). I - Misturas de herbicidas em pósemergência. Planta Daninha, v.3, n.2, p. 96107, 1980. 